\title{
The role of diffusion MRI in neuroscience
}

Yaniv Assaf ${ }^{1,2}$, Heidi Johansen-Berg ${ }^{3} \&$ Michel Thiebaut de Schotten ${ }^{4-6^{*}}$

${ }^{1}$ Sagol School of Neuroscience, Tel Aviv University, Tel Aviv, Israel

${ }^{2}$ Department of Neurobiology, George S. Wise Faculty of Life Sciences, Tel Aviv University, 69978 Tel Aviv, Israel

${ }^{3}$ FMRIB Centre, Nuffield Department of Clinical Neurosciences, University of Oxford, John Radcliffe Hospital, Oxford, OX3 9DU, UK

${ }^{4}$ Brain Connectivity and Behaviour Group, Frontlab, Brain and Spine Institute, Paris France.

${ }^{5}$ Sorbonne Universités, UPMC Univ Paris 06, Inserm, CNRS, Institut du cerveau et la moelle (ICM) - Hôpital Pitié-Salpêtrière, Boulevard de l'hôpital, F-75013, Paris, France

${ }^{6}$ Centre de Neuroimagerie de Recherche CENIR, Groupe Hospitalier Pitié-Salpêtrière, Paris, France

${ }^{*}$ Corresponding author: Michel Thiebaut de Schotten, Brain Connectivity and Behaviour Group, La Salpêtrière, 47 Boulevard de l'Hôpital, 75013 Paris, France.

Email address: michel.thiebaut@gmail.com 


\begin{abstract}
Diffusion weighted imaging has further pushed the boundaries of neuroscience by allowing us to peer farther into the white matter microstructure of the living human brain. By doing so, it has provided answers to fundamental neuroscientific questions, launching a new field of research that had been largely inaccessible. We will briefly summarise key questions, that have historically been raised in neuroscience, concerning the brain's white matter. We will then expand on the benefits of diffusion weighted imaging and its contribution to the fields of brain anatomy, functional models and plasticity. In doing so, this review will highlight the invaluable contribution of diffusion weighted imaging in neuroscience, present its limitations and put forth new challenges for the future generations who may wish to exploit this powerful technology to gain novel insights.
\end{abstract}


"We admire the contrivance of the fibre of every muscle, and ought still more to admire their disposition in the Brain, where an infinite number of them contained in a very small space, each execute their particular offices without confusion or disorder" 1.

As noted by Steno, post mortem dissections of the brain reveal an astonishing level of complexity, particularly within the white matter fibre pathways, composed of trillions of axons. As Isaac Newton intuitively suggested a few years later, these axons propagate electricity "along the solid filament of the nerves, from the outward organs of sense to the brain, and from the brain into the muscles" ${ }^{2}$. Anatomical exploration of the white matter connections of the human brain then becomes a new challenge, mixing medical knowledge with advanced practical skills of dissection and illustration (Figure 1).
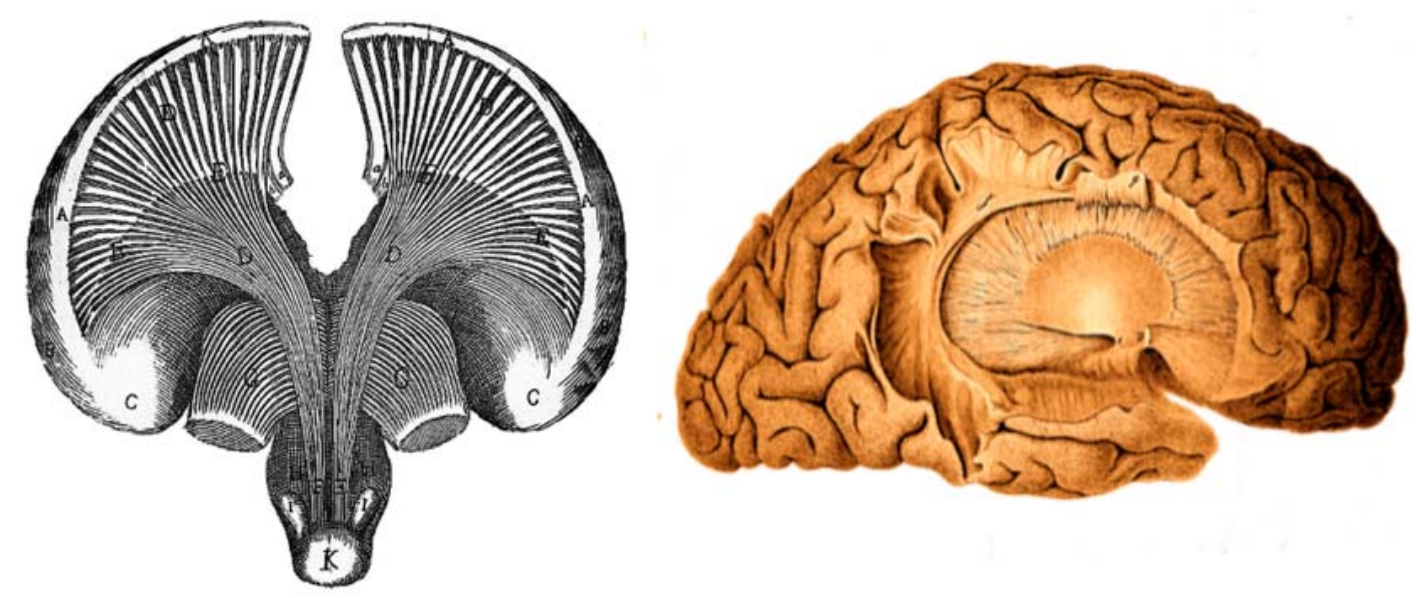

Figure 1: First drawings of white matter connection in the human brain. Left, brain dissection from Vieussens ${ }^{3}$ and right, brain dissection from Johann Christian Reil ${ }^{4}$.

These anatomical descriptions were a stepping-stone for the elaboration of new theories of brain function. This can be seen for example toward the end of the XIXth century, when Meynert extended Newton's vision even further, by introducing the possibility of reasoning occurring through the association of specialised areas of the brain via their white matter connections. The concept of associationism thus was born ${ }^{5}$.

Empirical validation of associationism came soon after with the study of patients with brain lesions and well-defined symptoms. Such studies required patience, as individual brain anatomy could only be revealed after death. So research projects might well last a lifetime for some or remain unachieved for others. Nevertheless, studies of single cases or case 
series revealed the first white matter biomarkers for neurological syndromes such as conduction aphasia ${ }^{6}$, transcortical motor aphasia, subcortical motor aphasia, transcortical sensory aphasia, subcortical sensory aphasia ${ }^{7}$, alexia without agraphia ${ }^{8}$, bilateral and unilateral apraxia ${ }^{9}$. These historical contributions demonstrated that the proper functioning of the brain can be disrupted even by distant lesions through disconnection and diaschisis mechanisms ${ }^{10,11}$.

Fundamental advances in our understanding of brain function came from this work. Nevertheless this static vision of the brain did not account for classical conditioning effects ${ }^{12}$ or memory ${ }^{13}$, or diaschisis ${ }^{14-16}$ phenomena that required notions of plasticity. Donald Hebb introduced this concept as follows "Let us assume that the persistence or repetition of a reverberatory activity (or "trace") tends to induce lasting cellular changes that add to its stability.... When an axon of cell $A$ is near enough to excite a cell $B$ and repeatedly or persistently takes part in firing it, some growth process or metabolic change takes place in one or both cells such that A's efficiency, as one of the cells firing $B$, is increased." With these words, Hebbian theory acknowledged the possibility for changes to occur in the brain, and provided a framework for conceptualising learning through the mechanisms of plasticity ${ }^{17}$. However, measures of plasticity were quite challenging, as they required the anatomical investigation of living samples with very invasive methods.

Decades later, magnetic resonance imaging (MRI) brought a new window on human brain anatomy. In 1985, a breakthrough came with the emergence diffusion-weighted MRI (DWI, ${ }^{18}$ ). DWI measures the diffusion of water molecules along different directions. Given that axons are impermeable they constrain water diffusion to their main direction. Hence, DWI indirectly assesses white matter microstructure. Further by piecing together local estimates of water diffusion orientation, main bundles of axons can be reconstructed. This technique clearly boosted research because of its non-invasiveness. Anatomical studies performed in living human brains were able to refine the description of large fiber bundles ${ }^{19,20}$, allowing for replication in large numbers of participants ${ }^{21,22}$ and enabling the discovery of inter-individual variability ${ }^{23,24}$. Functional models could now benefit from whole brain connectomes for the first time ${ }^{25}$, identifying new disconnection syndromes ${ }^{26}$ and allowing for new divisions of the cortex based on axonal inputs and outputs or connectivity based parcellation ${ }^{27,28}$. Finally, the structural connectome of an individual could be assessed different time points allowing for the investigation of white matter plasticity for the first time ${ }^{29}$.

Hence, in this review of the role of DWI in neuroscience we will first describe the anatomical advances provided by this method and will then survey its importance in the establishment of new brain models. Finally, we will review studies that investigated white 
matter plasticity. Hopefully, the ideas expressed in this review will provide a comprehensive understanding of the scientific question investigated with DWI and encourage new generations to pursue exploit this powerful technology to gain novel insights into human brain wiring.

\section{Part 1/ Anatomy}

Diffusion MRI provides different types of information about human brain anatomy. Local (voxel-wise) measures of diffusion properties can give insight into local white matter microstructure, whereas exploiting these measures to perform in-vivo tractography can provide information on the organisation of white matter at a systems level.

\section{Local measures of white matter microstructure}

Voxel-wise measures of diffusion properties, such as fractional anisotropy or mean diffusivity, are modulated by local tissue microstructure ${ }^{30}$. For example, studies in model systems show that fractional anisotropy increases with increasing packing density or decreasing axon diameter ${ }^{31}$, and decreases with reductions in myelin ${ }^{32}$. However, although empirical or simulation studies can clearly demonstrate that varying these tissue properties modulates diffusion parameters, we are still faced with an inverse problem when trying to interpret an observed difference in diffusion parameters (e.g. reduced fractional anisotropy), as there is not a one to one relationship between a given diffusion parameter and the underlying tissue structure ${ }^{33-37}$. Nevertheless, diffusion parameters provide useful noninvasive measures of local tissue microstructure, with sensitivity to features including membrane integrity, myelin thickness, axon diameter and packing density. These physical characteristics of the white matter fibre bundle will have consequences for the physiological functioning of that bundle, affecting properties such as conduction time, refractory time, probability of transmission or even synchronisation of signals across a distributed corticocortical network. Variations in these physiological properties may in turn be expected to give rise to variation in behavioural outputs ${ }^{33,38,39}$.

For instance, left and right hemispheres show variation in function as well as in anatomy. Diffusion parameters' comparison between the two hemispheres indicated increased fractional anisotropy in the left hemisphere in the external capsule ${ }^{40}$, cingulum bundle ${ }^{41}$ and perisylvian white matter ${ }^{42}$ thought to support left hemispheric dominance for language functions ${ }^{43,44}$. Right asymmetries were also identified in the dorsal fronto-parietal white matter ${ }^{42}$ that could be related to the right hemispheric dominance for spatial processing of information. However, the high variability between subject and the lack of behavioural 
measures in these preliminary studies did not allow a solid relationship to be drawn between voxelwise measure of interhemispheric differences and functional dominance. Particularly, the relationship between language lateralisation and structural connectivity measures in the language system remains intricate ${ }^{43,45}$.

Further studies have shown that individual differences in measures of local white matter microstructure correlate with variations in physiological properties of the fiber pathways ${ }^{46-52}$. For example, paired-pulse transcranial magnetic stimulation can be used to probe the functional connectivity of a cortico-cortical connection. A conditioning pulse applied to dorsal premotor cortex of one hemisphere will modulate the excitability of the primary motor cortex in the other hemisphere; the degree of modulation can be used to estimate functional connectivity between the two cortical areas. Individual differences in this measure were found to correlate with variation in white matter fractional anisotropy (FA), such that individuals with stronger functional connectivity had higher FA in callosal or subcortical white matter pathways between premotor and motor cortex ${ }^{53}$. This supports the idea that variation in white matter microstructure is associated with variation in the physiological properties of those fiber bundles.

Advanced diffusion weighting imaging analyses provide estimates of the axon diameter distribution or fibre composition along with other physical properties, such as the intra-axonal resistance, membrane resistance and capacitance, etc, help determine many important functional properties of nerves, such as their conduction velocity or rate of information transfer ${ }^{54-58}$. Neural pathways that are characterized by fast reaction times (e.g. within the motor system) will also exhibit higher percentage of large-diameter axons. On the other hand, pathways that show slow conduction velocity will also exhibit a larger population of smaller axons or even non-myelinated axons. Therefore, it is only logical to assume that the properties of axon diameter distribution will have critical role on healthy central nervous system functioning and will be dramatically affected in abnormal conditions and disease.

Despite the fundamental new insights it provides, diffusion weighted imaging has several important limitations. The key limitation is implicit in the diffusion tensor model (DTI, ${ }^{59}$ ). This assumption oversimplifies the true motion of water within brain tissue. The practical consequence of this over-simplicity of the diffusion tensor model is that the common DTI indices, mean diffusivity and FA, are non-specific to any particular tissue compartment. Features of microstructure, such as cell size, density, permeability and orientation distribution, all affect DTI indices and changes in the indices are impossible to associate with more specific changes in microstructural features. Recent trends aim to use more sophisticated models of diffusion in order to measure microstructural features directly ${ }^{60,61}$. 
One such approach for modelling the diffusion signal (instead of DTI) is to devise a mathematical formalism that is guided by tissue geometry. Yet, anyone who has looked down a microscope at a brain section would have been impressed by the complexity of the white matter geometry ${ }^{36,62}$. Cells of different shapes and sizes with processes spreading at different scales and orientations depict a mess of geometries at the micron-scale. Yet even at a lower-level of magnification, where cell layers and fibre bundles are visible, complexity arises where fibres cross, disperse and fan within hundreds of microns.

Pioneering work by Stanisz and collaborators attempted to reduce the complexity of neural tissue modelling by introducing a two-compartment geometrical framework that includes diffusion within spheres and cylinders ${ }^{63}$. Further works have suggested that diffusion within the confined boundaries of cells and axons can be regarded as restricted diffusion. Under this approach it is hypothesized that the geometry of the tissue affects the diffusivity of water molecules. For example, it is reasonable to assume that water diffusion within the axon will be restricted by the myelin membrane while elsewhere it will be only hindered or free. This is the basis for the composite hindered and restricted model of diffusion (CHARMED) ${ }^{60,64}$. In CHARMED, restricted diffusion in the intra-axonal space is modelled as diffusion within impermeable cylinders ${ }^{64-66}$. As a consequence, the CHARMED model allows enhanced characterization of the axonal water compartment. One of the advantages of CHARMED is that it is possible to reconstruct the $3 \mathrm{D}$ displacement distribution function for each of the components (hindered and restricted). Thus, it is possible to extract physically meaningful parameters for each of the diffusing components; these parameters include the diffusivity of the extra-axonal matrix (diffusivity of the hindered part), the axonal density (the volume fraction of the restricted part), and the fibres directions (the orientation density function of the restricted part). While the CHARMED model provides a conceptual framework to separate different modes of diffusion and relate them to tissue compartments, it allows modelling of 2-3 different fibre orientations with accuracy limited by the number of measured directions ${ }^{60}$. Subsequent works tried to expand the CHARMED model to include fibre dispersion and fanning within a voxel and increase the accuracy and orientation estimation of the model ${ }^{67-71}$. Noteworthy is the NODDI framework which expands CHARMED to model also dispersion of fibre orientation but with optimized acquisition and analysis pipelines ${ }^{69}$.

Neural tissue is complex, and it should be realized that there will not be a single model that can capture all the details and complexity of different neural compartments ${ }^{62,72}$. The different abovementioned models (and others) try to separate different features of interest of the tissue. Obviously including too many free parameters in the model will lead to 
computational problems such as over fitting and other optimization and data fitting issues. Thus, the optimal model for diffusion imaging depends on the research question. For example, an important feature of white matter that is not modelled in CHARMED or NODDI is axon diameter ${ }^{73-75}$. Being an important feature of brain connectivity with implications for conduction velocity and information transfer efficiency within the brain ${ }^{76,77}$, the in-vivo measurement of axonal diameter became another modelling challenge. In an extension of the CHARMED framework, called AxCaliber, the estimation of the axon diameter distribution became also feasible ${ }^{78,79}$. The idea behind AxCaliber is that each axon size will experience restricted diffusion at a different diffusion time. For example, an axon with a diameter of $1 \mathrm{um}$ will experience restricted diffusion already at very short diffusion times while a larger axon will experience restricted diffusion only when the diffusion time is increased. By acquiring a multi-diffusion time CHARMED data set it is possible to accurately estimate the axon diameter distribution function with the AxCaliber framework. In AxCaliber, unlike CHARMED, water diffusion is measured exactly perpendicular to the long axis of the fibers (this is a prerequisite of the model). It was found that by using a gamma function (with only 2 free parameters) it is possible to adequately estimate the axon diameter distribution function by AxCaliber ${ }^{79}$. 
(A)

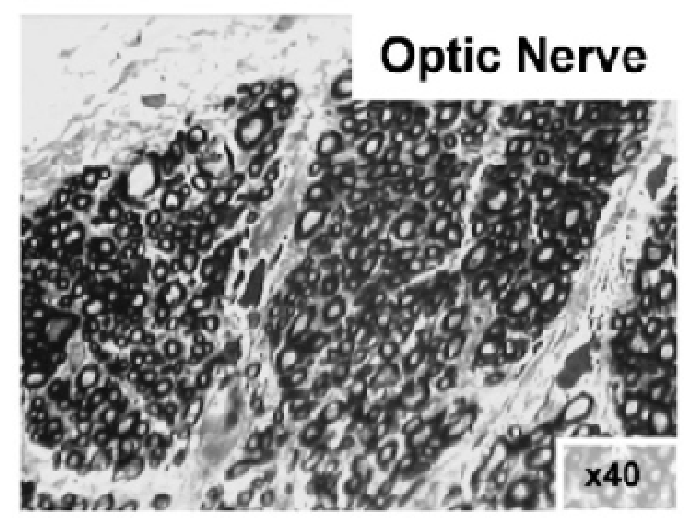

(C)

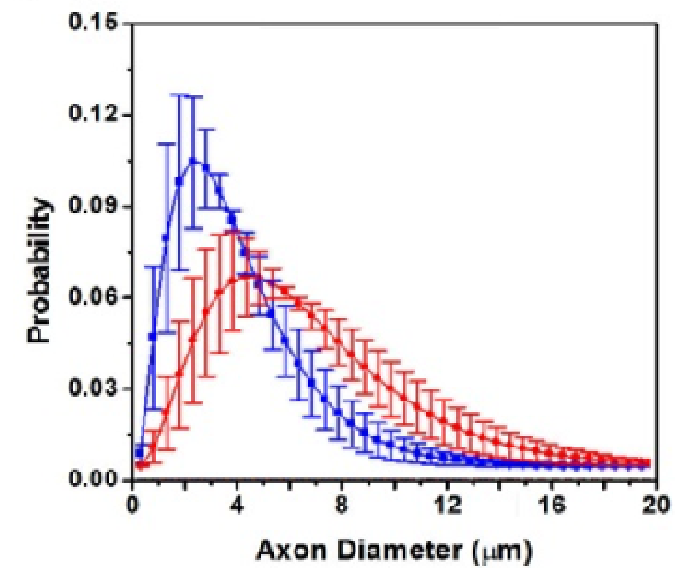

(B)
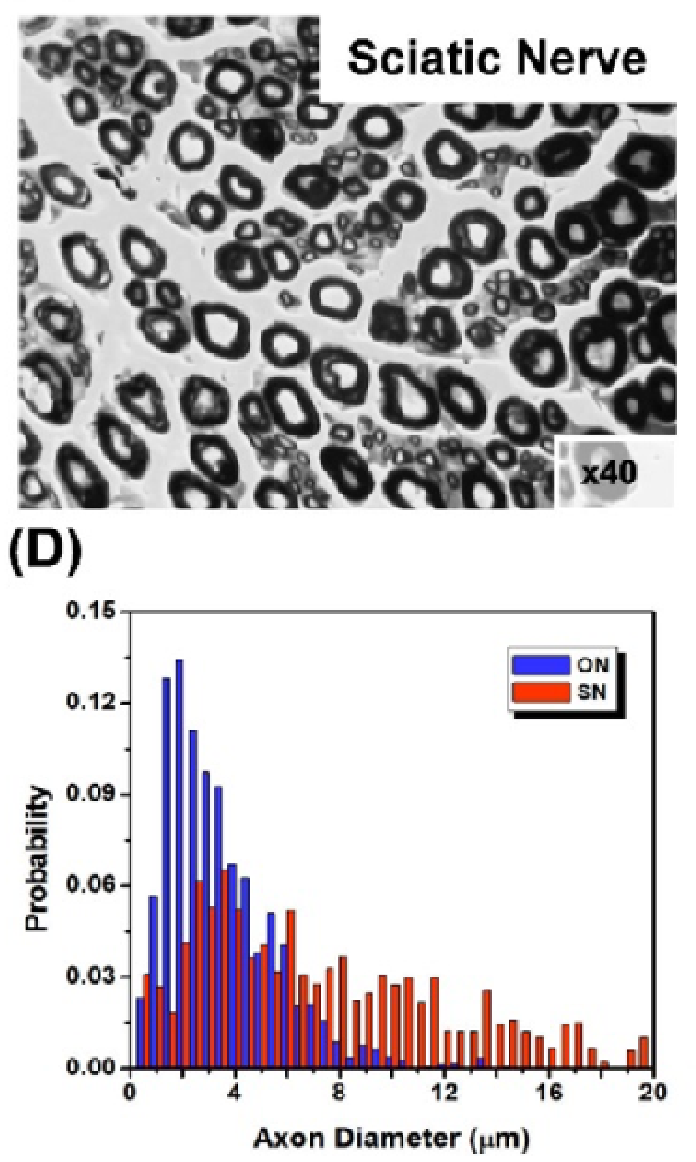

Figure 2: AxCaliber of porcine optic and sciatic nerves: $(A)$ and $(B)$ are electron microscope section of optic nerve (A) and sciatic nerve (B). (C) AxCaliber axon diameter distribution - (optic - blue, sciatic -red). (D) Axon diameter distribution derived from electron microscopy

The AxCaliber framework was verified on excised samples of optic and sciatic nerves. These two nerve samples have very different axon diameter distribution functions (Figure 2). The AxCaliber diameter distribution functions were in good agreement with the histological ones (Figure 2) ${ }^{79}$. In addition, AxCaliber was implemented to study the morphology of the corpus callosum (in-vivo). AxCaliber analysis was performed on a voxel-by-voxel basis providing for each the axon diameter distribution function for each voxel. These distributions were used as an input to a clustering algorithm in order to visualize regions with significantly different axon diameter distribution (ADD). The clustering based on the ADD was able to segment the corpus callosum into several regions that fit known morphological zones of those samples ${ }^{80}$ (Figure 3). Recently the axon diameter distribution was demonstrated in the human brain and also was shown to correlate with conduction velocity measures of 
interhemispheric transmission time ${ }^{81}$. Hence correlations between in vivo measures of axonal diameters and reaction time measures during cognitive paradigms will be of particular interest in near future.

It should be noted that the original AxCaliber framework suffers from several inherent limitations. The first is the need to measure the diffusion properties exactly perpendicular to the fibre orientation. This limited the application of the method to the corpus callosum. In a further development of the CHARMED and NODDI frameworks it was suggested that the mean axon diameter could be directly measured for any orientated fibre system ${ }^{82}$. The ActiveAx acquisition and analysis pipeline, although not measuring the entire axonal distribution probability function, provides an approach to estimate the mean axon diameter for the entire brain. Another limitation to measuring axonal diameter properties with diffusion imaging is the need to have high diffusion gradient amplitude in order to have comparable accuracy over a wide spread of axon diameters. It was shown, theoretically, that small axons ( $<1$ micron) will be inaccurately estimated with current gradient technology and will bias the overall measured axon diameter ${ }^{83,84}$. This measurement artefact is significantly minimized with new gradient technology providing high amplitudes of diffusion gradients $(300 \mathrm{mT} / \mathrm{m})^{85}$. Yet, other works suggested that the modelling algorithm can be further developed to cope with the abovementioned limitations by introducing additional features such as restricted diffusion within the extracellular space ${ }^{86-88}$. Yet, despite this limitation, the measurement of axonal properties provides an additional micro-structural feature that can better characterize brain connections and connectivity.

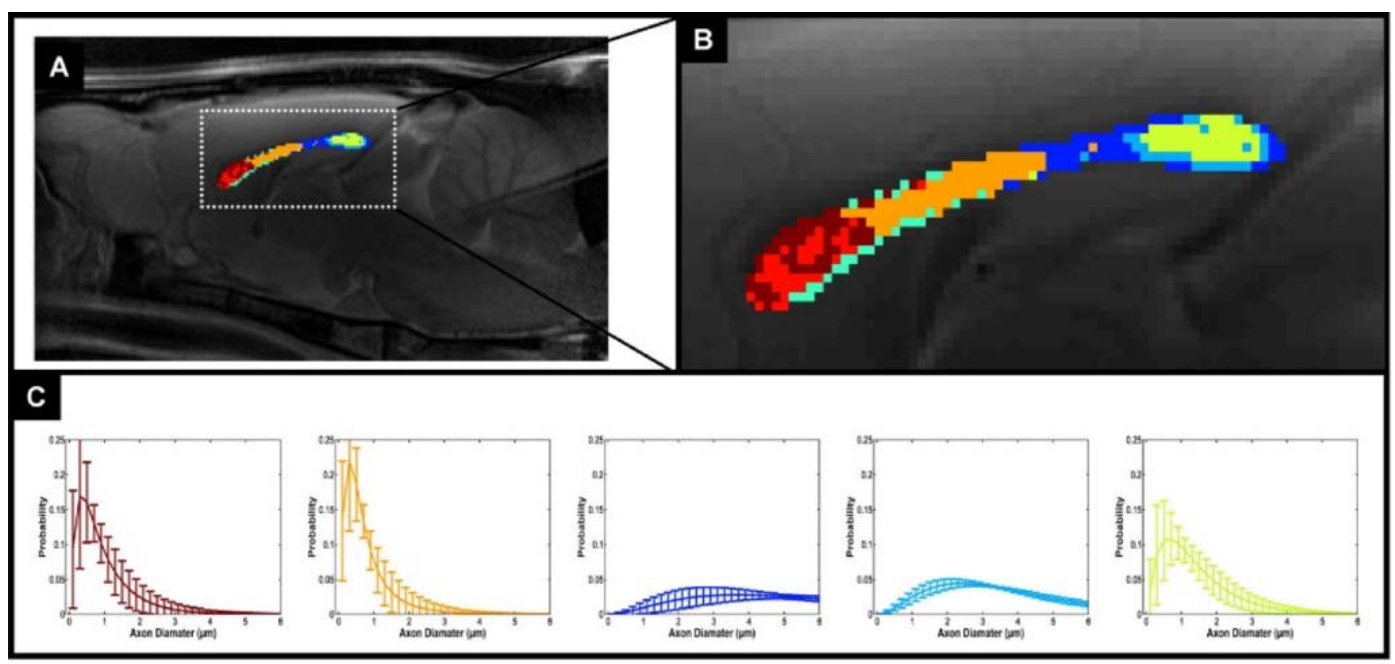

Figure 3: Cluster analysis of Ax-Caliber's ADD along the corpus callosum: (A) A midsagittal T2-weighted MRI with the AxCaliber clusters super-imposed, enlarged at (B). (C) The AxCaliber averaged ADDs for the different clusters given in (A) and (B). 


\section{Tractography to estimate long-range connectivity}

As mentioned above, local estimates of dominant diffusion directions can be followed to reconstruct estimates of fiber pathways. There are many different methodological approaches to performing diffusion tractography, as reviewed elsewhere in this special issue 37,89. From the neuroanatomical perspective, tractography allows us to estimate the organisation of major fibre pathways in the human brain (Figure 4) and to explore variation in the strength and organisation of these pathways between individuals or over time.

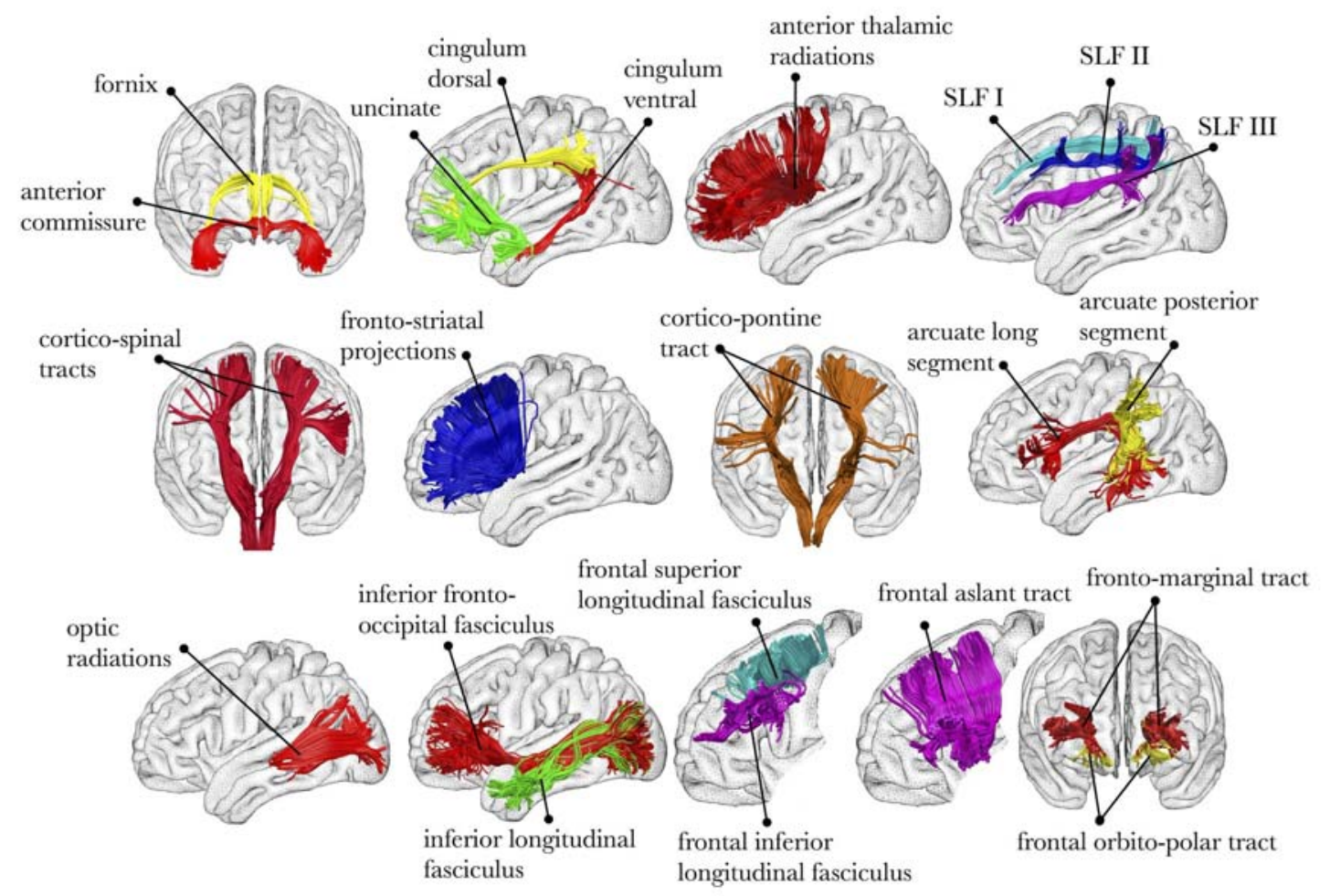

Figure 4: Virtual dissection of the major fibre pathways in the human brain ${ }^{90}$.

Early applications of diffusion tractography were able to provide the first 'in vivo dissections' and mapping of major white matter fiber bundles in the human brain with an increasing precision ${ }^{19,21,91-100}$ and led to the publication of several atlases ${ }^{101-103}$.

The use of tractography for anatomical studies has mostly depicted associative tracts (i.e. cortico-cortical connection) as they were defined in the early XIXth century (Figure 5a). Handling of tractography was indeed much easier than standard post mortem white matter dissections and led to the discovery of new associative tracts which were consequently replicated using standard post-mortem Klingler dissections ${ }^{104,105}$. In that sense tractography has boosted our anatomical knowledge of white matter pathways by providing an easier 
access to white matter connections ${ }^{106,107}$. For instance, much evidences from tractography, cross validated with post-mortem dissections, now converges toward a model of the arcuate fasciculus splitted into three branches (temporo-parietal, fronto-parietal and posterior parietotemporal, Figure $\mathbf{5 b}$ ). However, caution is required to be taken as many limitations in tractography may mislead neuroanatomists by piecing together different tracts segments into large single bundles ${ }^{37,89}$.

This is particularly the case for projection (i.e. subcortico-cortical) and commisural pathways (i.e. interhemispheric), which have been more challenging to dissect due to severe limitations in the tractography of complex white matter configurations (i.e crossing, fanning and kissing configuration) (Figure 5c). Although crossing has been the focus of interest of much work for the past 5 years, with very promising results particularly evident with the use of spherical deconvolution tractography 108-113 (Figure 5d), fanning and kissing configurations still remain a clear challenge in this field of research. The fanning limitation is characterised by an underestimation of the fibre count reaching an area and the kissing limitation by the misidentification of the correct group of fibres to track. Together, these two problems hamper progress in the depiction of the projection and commissural pathways ${ }^{114-}$ 116 . 

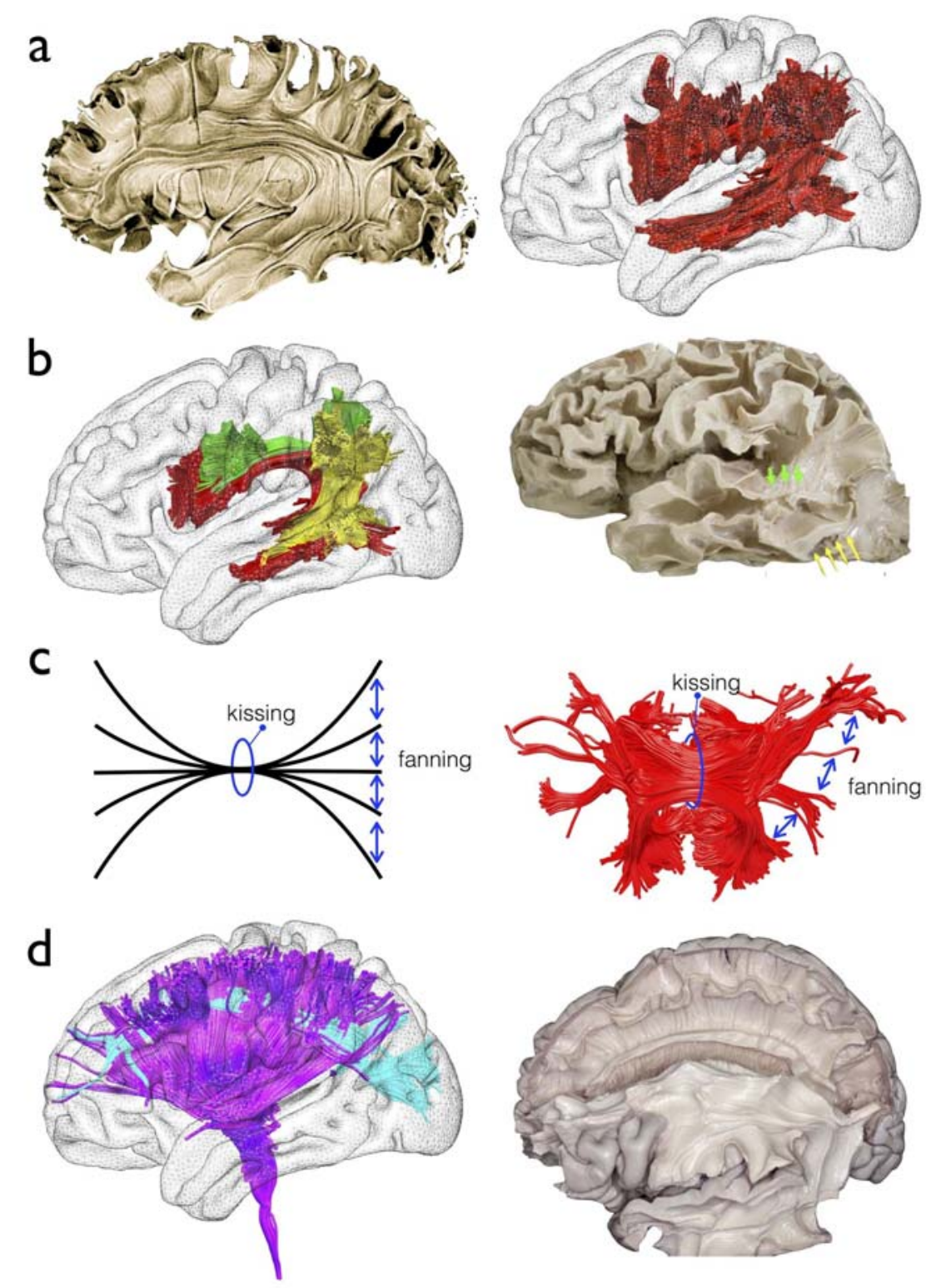

Figure 5: White matter anatomy from early tractography to advanced models. a) Standard anatomical description of the arcuate fasciculus (Left panel, ${ }^{104}$ ) replicated with diffusion weighted imaging tractography (Right panel, ${ }^{19}$ ) b) New anatomical model of the arcuate fasciculus (Left panel, ${ }^{20}$ ) validated with Klingler post-mortem dissection (Right panel, ${ }^{95}$ ) c) Model of white matter configurations that challenge classical tractography (Left panel), example of the tractography of the corpus callosum splenium showing the same limitation (Right panel) . d) First branch of the superior longitudinal fasciculus crossing with the corona radiata discovered in humans with advanced spherical deconvolution 
tractography (Left panel, ${ }^{77}$ ) later validated with Klingler post-mortem dissection (Right panel, ${ }^{117}$ )

\section{Tractography to divide grey matter into subregions}

At a cortical level, SMA and pre SMA, two areas working hierarchically in the control of action ${ }^{118}$ have a different pattern of connection with the rest of the brain. Exploiting this difference, connectivity information gained from diffusion tractography can be used to define the boundary between these two regions based purely on connectivity, driven by the fact that SMA shows a closer relationship with primary motor cortex whereas pre-SMA is more connected to the prefrontal cortex ${ }^{27}$. Indeed, connectivity-based parcellation has been used to define subdivisions across a range of different human cortical areas ${ }^{119-126}$, as well as to demonstrate homologies between human and monkey cortex ${ }^{127-133}$. Recently, diffusion tractography was used along with other multimodal structural and functional MRI data to generate a novel whole brain cortical parcellation using data from the Human Connectome Project (Figure $7 \mathrm{a},{ }^{126}$ ).

Alongside enthusiasm for the newfound ability to visualise white matter bundles in living human brains, have been notes of caution to keep in mind that tractography is not the same as invasive tract tracing. 'Gold standard' invasive tract tracing typically involves injecting a tracer into an area of interest, allowing it to be taken up by cells, and then observing it in interconnected regions after it has been transported there via anterograde and/or retrograde transport mechanisms. As such, invasive tract tracing involves tracing axonal pathways. By contrast, in diffusion tractography we are typically following estimates of the path of least resistance to diffusion. In many cases, this corresponds roughly to the path of the dominant fibre orientation, but in other cases it does not. There is therefore awareness that, as with any method in biology, diffusion tractography is susceptible to false negatives (inability to track pathways that we know exist) and false positives (tracking spurious pathways). Much valuable work has been done to try to validate diffusion tractography, giving us a clearer idea of the limitations and strengths of the method ${ }^{134-141}$. This is challenging work, requiring development of novel phantoms with realistic properties ${ }^{115,142}$, or meticulous reconstruction of fibre pathways from brain sections taken from tract tracing experiments ${ }^{143,144}$. Such work is encouraging but there is more to be done to allow neuroscientists to be able to interpret diffusion tractography results with confidence ${ }^{145}$. 
a

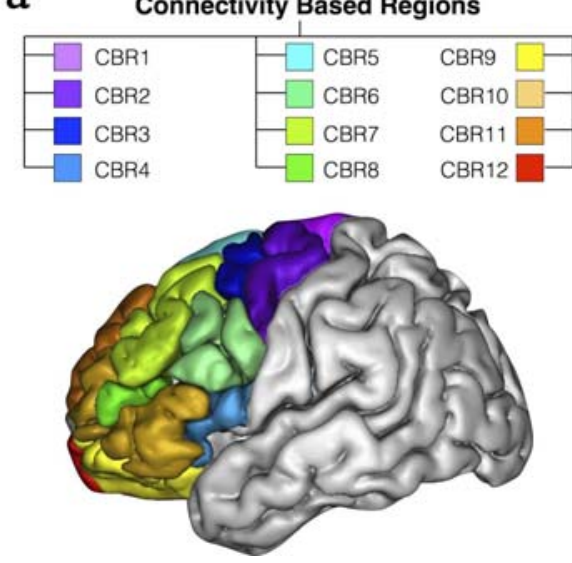

b

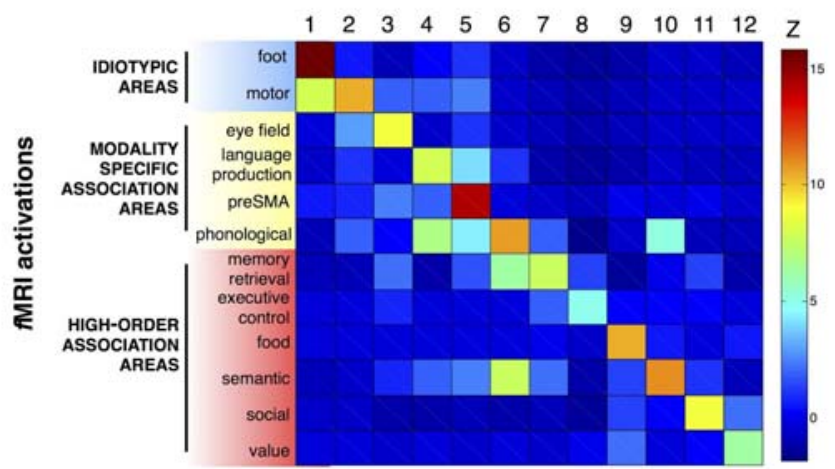

Figure 6: Connectivity-based parcellation of the frontal lobes. a) 3D lateral view of the brain and the 12 regions defined by the structural connections with the rest of the brain. b) functional specificity of the 12 connectivity based regions.

\section{Part 2/ Functional models}

Functional models of the brain originally emerged from the study of brain damaged patients ${ }^{146}$. The localisation of the lesion in the brain was indeed interpreted as the core origin of the functional impairment ${ }^{147}$. However, the localisation of the lesion appeared insufficient to explain the existence of patients with different lesions and similar symptoms. The idea emerged that the communication between these regions was impaired through a mechanism of white matter disconnection. Traditional model of disconnection syndromes includes conduction aphasia ${ }^{6}$, transcortical motor aphasia, subcortical motor aphasia, transcortical sensory aphasia, subcortical sensory aphasia ${ }^{7}$, alexia without agraphia ${ }^{8}$, bilateral and unilateral apraxia ${ }^{9}$. With the advent brain imaging the neuroimaging community focused on voxels independently ${ }^{148-150}$ without any attempts to capture correlation across them ${ }^{151,152}$, effectively masking disconnection syndromes ${ }^{153,154}$. The access to visualisation and mapping of white matter connections instead allowed for the investigation of white matter connections in patients and led to the discovery of new disconnection syndromes. For instance, visuospatial neglect, a severe neurological condition characterised by the loss of half of the visual field's awareness, is associated with the disruption of the fibres connecting the frontal to the parietal lobe ${ }^{26,153,155}$. Tractography also contributed to the establishment or confirmation of a new disconnection hypothesis for Gerstmann syndrome ${ }^{156}$, and neurodevelopmental hypoconnectivity hypotheses for psychopathy ${ }^{157}$, dyslexia ${ }^{158}$ as well as congenital prosopagnosia ${ }^{159}$. Conversely, aberrant/increased connections (i.e. 
hyperconnection) hypotheses have recently been suggested as a potential mechanisms for inattention in attention deficit hyperactive disorders ${ }^{160}$, auditory ${ }^{161-163}$ and visual hallucinations ${ }^{164}$ in schizophrenia. All these results demonstrate the utmost importance of brain connection to the proper functioning of the brain. Indeed brain areas deprived of their inputs (i.e. afferent connections) or outputs (i.e. efferent connections) will no longer be able to contribute anymore to the elaboration of the cognition and the behaviour.

With regards to effects on behaviour, studies have shown that individual differences in behavioural performance for a given task correlate with variation in white matter microstructure of task-relevant pathways, even in young healthy populations ${ }^{39,165} 38$. For example, as summarised in Figure 7, variation in bimanual co-ordination skill correlates with variation in fractional anisotropy in the body of the corpus callosum, a white matter area that contains transcallosal pathways between primary and supplementary motor areas ${ }^{166}$. Similar effects have been found in a wide range of sensory, motor and cognitive domains including for example vision ${ }^{167-169}$, audition ${ }^{170}$, motor skills ${ }^{171-175}$ and language ${ }^{176,177}$, literacy ${ }^{178-180}$, emotion ${ }^{181}$ and motivation ${ }^{182}$, visuospatial ${ }^{183}$, memory ${ }^{184}$ and executive function ${ }^{175,185,186}$ and individual characteristics such as creativity ${ }^{187}$, musical skills ${ }^{188}$ and personality ${ }^{189,190}$. 


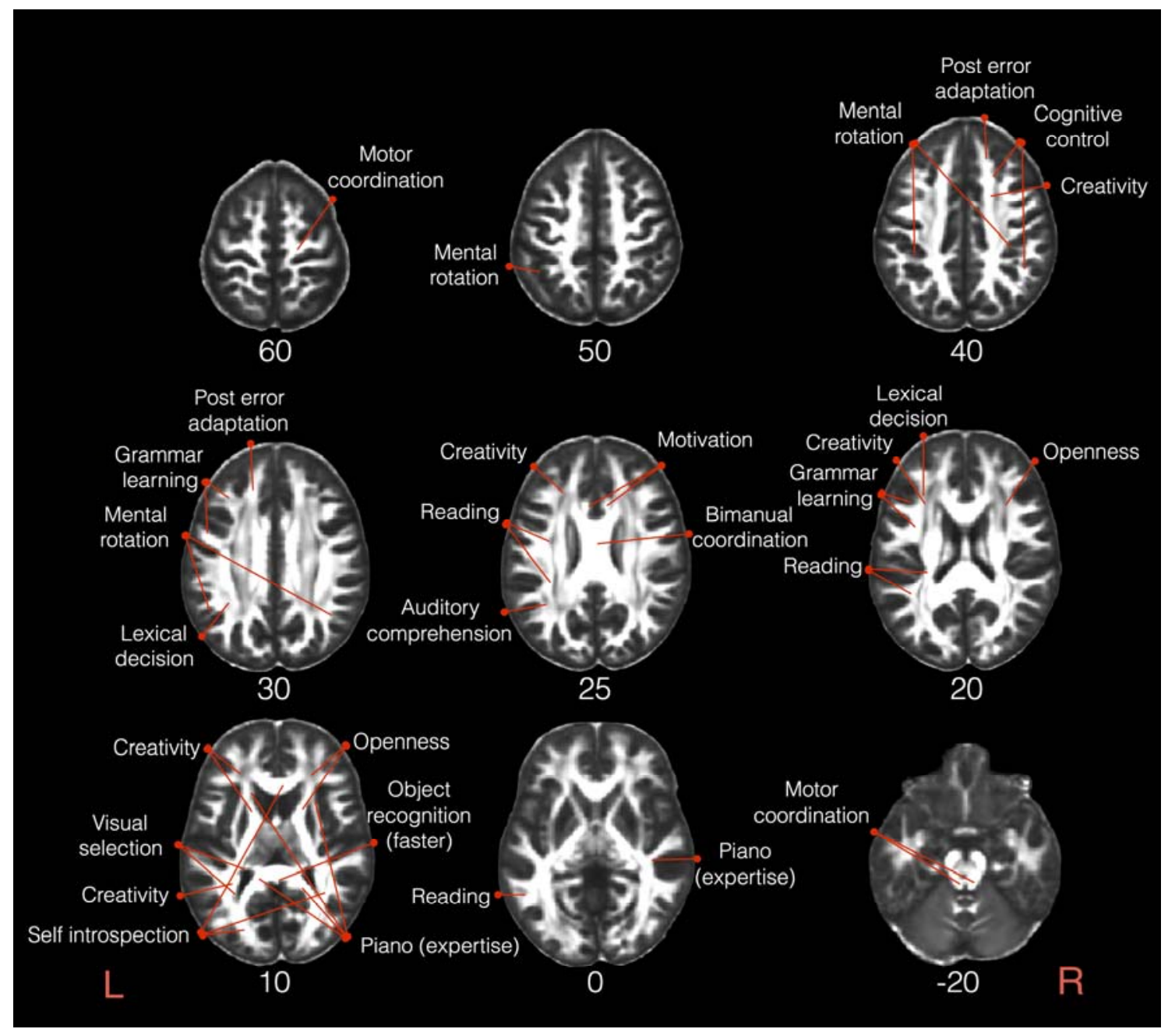

Figure 7: Correlations between individual differences in behavioural performance for a given task and variation in white matter microstructure. Axial slices are displayed in neurological convention. Numbers indicate MNI152 axial coordinates ${ }^{191}$. L, Left ; R, Right.

Such evidences suggest that the function of a brain area can be defined by its afferent connections from and efferent connection to other areas ${ }^{192-194}$. As reported in the previous section, brain regions can be characterised by their structural connectivity with the rest of the brain. Therefore, boundaries based on structural connectivity might well give a functional parcellation of the brain. Preliminary evidence starts to abound in this direction. For example, delineating subregions of human thalamus is important to be able to study the function of these regions in vivo and to be able to target specific nuclei for surgical interventions such as deep brain stimulation for movement disorders. However, divisions between thalamic nuclei are not visible on standard structural MRI. Using diffusion tractography, thalamic subregions can be reliably identified based on cortical connectivity patterns ${ }^{28}$. These connectivity-based divisions have been shown to have functional 
relevance ${ }^{195,196}$, and could be useful for individualised neurosurgical planning ${ }^{197}$. Recently, tractography revealed a division of the frontal lobes in 12 areas characterised by their connection with the rest of the brain and a clear-cut functional specificity (Figure $5 b)^{126}$. Hence model of structural connectivity assessed with tractography seems to capture the functional organisation of the brain.

However, the past two decades have been marked by the discovery of large interindividual variability in brain structure and function (i.e. different phenotype), creating additional challenges in furthering the understanding of the brain and a lack of models to explain its functioning ${ }^{198-201}$. Studies have begun to explore and describe these pathways across large numbers of individuals $24,116,202$. Just as studies have found that individual differences in behaviour correlate with variation in local white matter microstructure, so too have tractography studies found that variation in the 'strength' or organization of white matter fibres relate to variations in behaviour. For instance, language areas and their interconnections are predominantly represented in the left hemisphere for most but not all healthy participants ${ }^{203,204}$. However, individuals vary in the degree of lateralisation and people with more symmetric patterns of connection have been shown to perform better at episodic memory tasks ${ }^{203}$. These differences are important consideration for the field of clinical neuroscience. Forkel et al. ${ }^{205}$ demonstrated that the phenotype of the structural network supporting language (i.e. arcuate fasciculus) may interact with recovery after a stroke in the left hemisphere. Additionally, Lunven et al. ${ }^{206}$ reported that the strength of interhemispheric communication is important for the recovery of visuospatial neglect after a stroke in the right hemisphere (see ${ }^{207,208}$ for extensive reviews on the role of diffusion MRI in clinical neurosciences). Hence the study of inter-individual variability is a new line of research directly accessible in large scale projects such as the Human Connectome Project (https://www.humanconnectome.org), where high quality diffusion MRI data have been acquired in 1200 subjects and openly shared with the community ${ }^{209}$. Using diffusion weighted imaging tractography to characterise the functional specialisation of brain areas at the individual level may therefore benefit the domain of inter-individual variability, providing a more tailored brain model when doing group comparisons eventually making methods like spatial registration and smoothing obsolete.

\section{Part 3/ Measures of Plasticity}

Until the mid '90s, research on white matter was limited to histological investigations of its anatomy, for two reasons: 1) There was no in-vivo and non-invasive imaging method that could provide quantitative measures of the white matter; 2) it was thought that in the fully developed and healthy brain, the micro-structure of white matter should be roughly stable 
and fixed. Nevertheless, recent studies suggest that the white matter can undergo changes following training or cognitive experience. Such studies coined the term white matter plasticity.

Neuroplasticity, the functional and structural re-organization capacity of the brain may occur at several levels (from molecular to regional changes) and time-scales (seconds ${ }^{210,211}$ to years ${ }^{212}$ ). Obviously, the definition of neuroplasticity and its investigation are centred around neurons and less on white matter. Nevertheless, the scope of neuroplasticity is wide, ranging from short-term changes at the synapse through long-term potentiation (LTP) and depression (LTD) mechanisms through long-lasting new neuronal connections (dendritic trees) ${ }^{213-218}$.

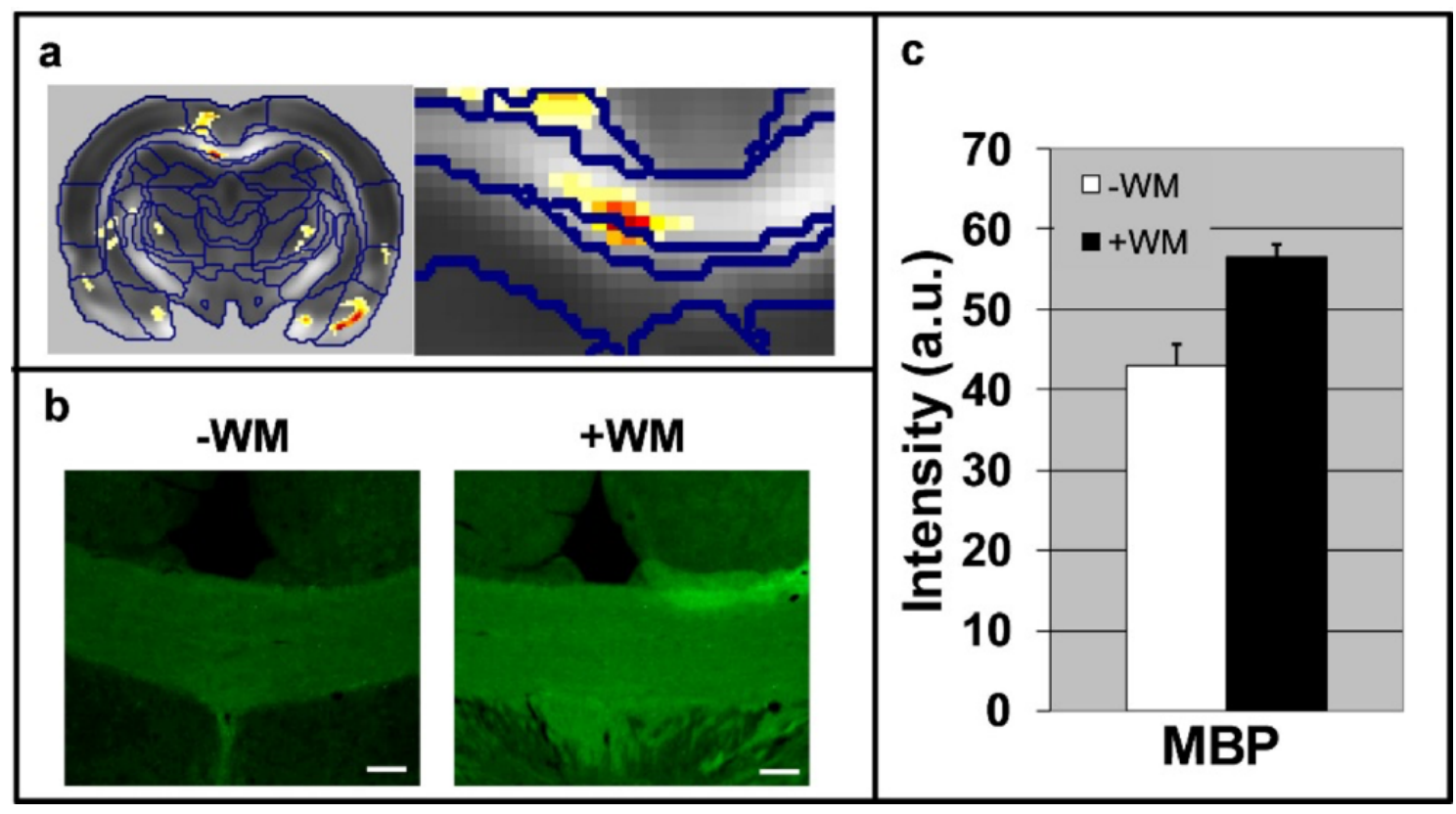

Figure 8: White matter plasticity following a 5-day water maze. (a) Statistical parametric maps of interaction in FA values between scan time (pre vs. post water maze) and group (learning vs. control). An enlargement of the corpus callosum region is shown on the right. (b) Immunohistochemical staining (x10 magnification) of the CC for MBP. Note the increase in MBP immuno-reactivity in the CC after the water maze task. (c) Quantification of the immunoreactivity (staining intensity) in the $C C(P<0.05)$.

Pioneering studies revealed that new white matter projections can be formed following extensive learning procedures ${ }^{219,220}$. These studies, performed on post-mortem monkey brains using tracer methods revealed that the brain can rewire itself concomitantly to cortical 
neuroplasticity ${ }^{221}$. Recent works utilized diffusion tensor imaging to reveal white matter changes following long term training (weeks to months) ${ }^{180,188,222}$. These studies suggested that diffusion imaging can be sensitive to white matter plasticity. Recent evidences showed that following only a 5-day water maze task, in addition to significant cortical plasticity, white matter plasticity in the corpus callosum could be detected with DTI ${ }^{223}$. Histology showed that this plasticity, characterized by increase in FA, is also manifested by elevated levels of myelin (Figure 6). In addition, a recent molecular imaging study suggests that already following action potentials, signalling mechanisms control oligodendrocyte myelin formation 224. This experiment was conducted on cultured neural tissue. Indeed, a recent study showed that 2 hours of spatial navigation task are sufficient to cause diffusion changes in the fornix. All these studies on plasticity are not exempt of limitation ${ }^{225}$ and future research is needed in order to strengthen that field.

These experiments, although performed on different species and samples (human, rodents and tissue culture) suggest that the white matter is a dynamic tissue. Yet, what exactly happens in the white matter is not fully understood and the temporal evolution of this phenomenon is uncharted. Specifically, a significant impact on neuroscience will be the demonstration of white matter plasticity in the human brain following short episodes (minutes/hours) of training. We anticipate that short-term white matter plasticity will be stimulate different mechanism from long term plasticity, however, DTI might be not sensitive and specific enough to demonstrate that difference. More specific methods such as CHARMED and AxCaliber could provide the enhanced sensitivity and specificity needed for comprehensive characterization of this phenomenon. Nevertheless, once white matter plasticity mechanisms can be resolved with MRI, these kinds of experiments could shed a new light on brain physiology and provide a whole new definition to the concept of brain connectivity.

\section{Conclusion}

Over the past 20 years, diffusion weighted imaging has proven to be an indispensable approach for the study of white matter. It has provided invaluable insight into neuroanatomy, which has led to the discovery of new pathways, and refinement of what we already knew. Notably, diffusion weighted imaging has demonstrated the existence of a clear organisation and a true inter-individual variability in the way that the brain is connected, and that this variability directly impacts the functioning of the brain. Finally, diffusion imaging offered the unique opportunity to directly quantify brain plasticity. However, while reducing the gap between direct biological and indirect DWI quantification of brain tissues continues to be a 
challenge, it is a necessity for future generations who may wish to exploit this powerful technology to gain novel insights.

\section{Acknowledgements}

We wish to thank Lauren Sakuma for useful discussion. This work was supported by the 'Agence Nationale de la Recherche' [grants number ANR-10-IAIHU-06 and number ANR-13JSV4-0001-01].

\section{REFERENCES}

1. Steno N. Discour de Monsieur Stenon sur l'anatomie du cerveau, Paris, Ninville. second edition ed. San Francisco, CA: Norman Publishing; 1669.

2. Newton I. Philosophiæ Naturalis Principia Mathematica. Benjamin Motte; 1687.

3. de Vieussens R. Neurographia universalis. Certe: Lyons; 1684.

4. Reil J. Die vördere Commissur im großen Gehirn Archiv für die Physiologie. 1812;11:89-100.

5. Meynert T. A Clinical Treatise on Diseases of the Fore-brain Based Upon a Study of Its Structure, Functions, and Nutrition. Translated by Bernard Sachs. New York: G.P. Putnam's Sons; 1885.

6. Wernicke C, Eggert G. Der Aphasische Symptomencomplex. Ein psychologische Studie auf anatomischer Basis. . 1874.

7. $\quad$ Lichtheim L. On aphasia. Brain. 1885;7:433-484.

8. Dejerine J. Contribution a l'étude anatomo-pathologique et clinique des differentes variétés de cécité-verbale. Mém Soc Biol. 1892;4:61-90.

9. Liepmann H. Apraktishe Störungen. In: Kramer $\mathrm{IHCaF}$, ed. Lehrbuch der Nervenkrakheiten. Berlin: Springer; 1925:408-416.

10. Monakow CV. Gehirnpathologie. Vienna: Hölder A. ; 1897.

11. Monakow CV. Die Lokalisation im Grosshirn und der Abbau der Funktion durch kortikale Herde. J. F. Bergmann; 1914.

12. Pavlov IP. Conditioned Reflexes: An Investigation of the Physiological Activity of the Cerebral Cortex. London: Oxford University Press; 1927.

13. Lashley KS. Studies of Cerebral Function in Learning. II. The Effects of Longcontinued Practice upon Localization. J Comp Psychol. 1921:11453-11468.

14. Price CJ, Warburton EA, Moore CJ, Frackowiak RSJ, Friston KJ. Dynamic diaschisis: anatomically remote and context-sensitive human brain lesions. Journal of cognitive neuroscience. 2001;13(4):419-429.

15. Finger S, Koehler PJ, Jagella C. The Monakow concept of diaschisis: origins and perspectives. Arch Neurol. 2004;61(2):283-288.

16. Carrera E, Tononi G. Diaschisis: past, present, future. Brain. 2014;137(Pt 9):24082422.

17. Hebb DO. The Organization of Behavior: A Neuropsychological Theory. New York: Wiley and Sons; 1949.

18. Le Bihan D, Breton E. Imagerie de diffusion in-vivo par résonance magnétique nucléaire. Comptes rendus de l'Académie des sciences. 1985;301:1109-1112.

19. Catani M, Howard RJ, Pajevic S, Jones DK. Virtual in vivo interactive dissection of white matter fasciculi in the human brain. Neurolmage. 2002;17(1):77-94.

20. Catani $\mathrm{M}$, Jones $\mathrm{DK}$, ffytche $\mathrm{DH}$. Perisylvian language networks of the human brain. Annals of Neurolology. 2005;57(1):8-16. 
21. Catani M, Thiebaut de Schotten M. A diffusion tensor imaging tractography atlas for virtual in vivo dissections. Cortex. 2008;44(8):1105-1132.

22. Thiebaut de Schotten M, Kinkingnehun S, Delmaire $C$, et al. Visualization of disconnection syndromes in humans. Cortex. 2008;44(8):1097-1103.

23. Ciccarelli O, Catani M, Johansen-Berg H, Clark CA, Thompson A. Diffusion-based tractography in neurological disorders: concepts, applications, and future developments. Lancet neurology. 2008;7(8):715-727.

24. Thiebaut de Schotten M, ffytche DH, Bizzi A, et al. Atlasing location, asymmetry and inter-subject variability of white matter tracts in the human brain with MR diffusion tractography. Neuroimage. 2011;54(1):49-59.

25. Bullmore E, Sporns O. Complex brain networks: graph theoretical analysis of structural and functional systems. Nat Rev Neurosci. 2009;10(3):186-198.

26. Thiebaut de Schotten M, Urbanski M, Duffau H, et al. Direct evidence for a parietalfrontal pathway subserving spatial awareness in humans. Science. 2005;309(5744):2226-2228.

27. Johansen-Berg H, Behrens TE, Robson MD, et al. Changes in connectivity profiles define functionally distinct regions in human medial frontal cortex. ProcNatlAcadSciUSA. 2004;101(36):13335-13340.

28. Behrens TE, Johansen-Berg $\mathrm{H}$, Woolrich MW, et al. Non-invasive mapping of connections between human thalamus and cortex using diffusion imaging. Nat Neurosci. 2003;6(7):750-757.

29. Sagi Y, Tavor I, Hofstetter S, Tzur-Moryosef S, Blumenfeld-Katzir T, Assaf Y. Learning in the fast lane: new insights into neuroplasticity. Neuron. 2012;73(6):11951203.

30. Beaulieu C. The biological basis of diffusion anisotropy In: Johansen-Berg $\mathrm{H}$, Behrens TEJ, eds. Diffusion MRI: From quantitative measurement to in-vivo neuroanatomy. London: Elsevier; 2014.

31. Takahashi M, Hackney DB, Zhang G, et al. Magnetic resonance microimaging of intraaxonal water diffusion in live excised lamprey spinal cord. Proc Natl Acad Sci U $S$ A. 2002;99(25):16192-16196.

32. Gulani V, Webb AG, Duncan ID, Lauterbur PC. Apparent diffusion tensor measurements in myelin-deficient rat spinal cords. Magnetic resonance in medicine : official journal of the Society of Magnetic Resonance in Medicine / Society of Magnetic Resonance in Medicine. 2001;45(2):191-195.

33. Zatorre RJ, Fields RD, Johansen-Berg $\mathrm{H}$. Plasticity in gray and white: neuroimaging changes in brain structure during learning. Nat Neurosci. 2012;15(4):528-536.

34. Basser PJ. Historical perspectives and future outlook of diffusion MRI. NMR Biomed. this issue.

35. Alexander D, Dyrby T, Nilsson M, Zhang G. Imaging brain microstructure with diffusion MRI: Practicality and applications. NMR Biomed. this issue.

36. Caspers S, Axer M. Decoding the microstructural correlate of diffusion MRI. NMR Biomed. this issue.

37. Jeurissen B, Descoteaux M, Mori S, Leemans A. Diffusion MRI Fiber tractography of the brain. NMR Biomed. this issue.

38. Kanai R, Rees $G$. The structural basis of inter-individual differences in human behaviour and cognition. Nat Rev Neurosci. 2011;12(4):231-242.

39. Johansen-Berg $\mathrm{H}$. Behavioural relevance of variation in white matter microstructure. Curr Opin Neurol. 2010;23(4):351-358.

40. Kubicki M, Westin CF, Maier SE, et al. Uncinate fasciculus findings in schizophrenia: a magnetic resonance diffusion tensor imaging study. Am $J$ Psychiatry. 2002;159(5):813-820.

41. Kubicki M, Westin CF, Nestor PG, et al. Cingulate fasciculus integrity disruption in schizophrenia: a magnetic resonance diffusion tensor imaging study. Biol Psychiatry. 2003;54(11):1171-1180. 
42. Park HJ, Westin CF, Kubicki M, et al. White matter hemisphere asymmetries in healthy subjects and in schizophrenia: a diffusion tensor MRI study. Neurolmage. 2004;23(1):213-223.

43. Piervincenzi C, Petrilli A, Marini A, Caulo M, Committeri G, Sestieri C. Multimodal assessment of hemispheric lateralization for language and its relevance for behavior. Neuroimage. 2016;142:351-370.

44. Budisavljevic S, Dell'Acqua F, Rijsdijk FV, et al. Age-Related Differences and Heritability of the Perisylvian Language Networks. J Neurosci. 2015;35(37):1262512634.

45. Lopez-Barroso D, Catani M, Ripolles P, Dell'Acqua F, Rodriguez-Fornells A, de Diego-Balaguer $\mathrm{R}$. Word learning is mediated by the left arcuate fasciculus. Proc Natl Acad Sci U S A. 2013;110(32):13168-13173.

46. Wahl M, Lauterbach-Soon B, Hattingen $\mathrm{E}$, et al. Human motor corpus callosum: topography, somatotopy, and link between microstructure and function. $J$ Neurosci. 2007;27(45):12132-12138.

47. Kloppel S, Baumer T, Kroeger J, et al. The cortical motor threshold reflects microstructural properties of cerebral white matter. Neuroimage. 2008;40(4):17821791.

48. Whitford TJ, Kubicki M, Ghorashi S, et al. Predicting inter-hemispheric transfer time from the diffusion properties of the corpus callosum in healthy individuals and schizophrenia patients: a combined ERP and DTI study. Neuroimage. 2011;54(3):2318-2329.

49. Stufflebeam SM, Witzel T, Mikulski S, et al. A non-invasive method to relate the timing of neural activity to white matter microstructural integrity. Neuroimage. 2008;42(2):710-716.

50. Roberts TP, Lanza MR, Dell J, et al. Maturational differences in thalamocortical white matter microstructure and auditory evoked response latencies in autism spectrum disorders. Brain Res. 2013;1537:79-85.

51. Vandermosten M, Poelmans H, Sunaert S, Ghesquiere P, Wouters J. White matter lateralization and interhemispheric coherence to auditory modulations in normal reading and dyslexic adults. Neuropsychologia. 2013;51(11):2087-2099.

52. O'Donnell L, Dadduci A, Wasserman D, Lenglet C. Advances in computational and statistical diffusion MRI. NMR Biomed. this issue.

53. Boorman ED, O'Shea J, Sebastian C, Rushworth MF, Johansen-Berg H. Individual differences in white-matter microstructure reflect variation in functional connectivity during choice. Curr Biol. 2007;17(16):1426-1431.

54. Hursh JB. The properties of growing nerve fibers. Am J Physiol. 1939;127(1):140153.

55. Ritchie JM. On the relation between fibre diameter and conduction velocity in myelinated nerve fibres. Proc R Soc Lond B Biol Sci. 1982;217(1206):29-35.

56. Waxman SG. Determinants of conduction velocity in myelinated nerve fibers. Muscle Nerve. 1980;3(2):141-150.

57. Waxman SG, Kocsis JD, Stys PK. The axon : structure, function, and pathophysiology. New York: Oxford University Press; 1995.

58. Tasaki I, Ishii K, Ito H. On the Relation Between the Conduction-Rate, the FiberDiameter and the Internodal Distance of the Medullated Nerve Fiber. Jpn J Med Sci III, Biophysics. 1943;9:189-199.

59. Basser PJ. Inferring microstructural features and the physiological state of tissues from diffusion-weighted images. NMR Biomed. 1995;8(7-8):333-344.

60. Assaf Y, Basser PJ. Composite hindered and restricted model of diffusion (CHARMED) MR imaging of the human brain. Neuroimage. 2005;27(1):48-58.

61. Cohen Y, Assaf Y. High b-value q-space analyzed diffusion-weighted MRS and MRI in neuronal tissues - a technical review. NMR Biomed. 2002;15(7-8):516-542.

62. Roebroeck A, Miller K, Aggarwal M. Ex vivo diffusion MRI of the brain: Technical challenges and recent advances. NMR Biomed. this issue. 
63. Stanisz GJ, Szafer A, Wright GA, Henkelman RM. An analytical model of restricted diffusion in bovine optic nerve. Magn Reson Med. 1997;37(1):103-111.

64. Assaf Y, Freidlin RZ, Rohde GK, Basser PJ. New modeling and experimental framework to characterize hindered and restricted water diffusion in brain white matter. Magn Reson Med. 2004;52(5):965-978.

65. Neuman $\mathrm{CH}$. SPIN-ECHO OF SPINS DIFFUSING IN A BOUNDED MEDIUM. Journal of Chemical Physics. 1974;60(11):4508-4511.

66. Codd SL, Callaghan PT. Spin Echo Analysis of Restricted Diffusion under Generalized Gradient Waveforms: Planar, Cylindrical, and Spherical Pores with Wall Relaxivity. J Magn Reson. 1999;137(2):358-372.

67. Jespersen SN, Bjarkam CR, Nyengaard JR, et al. Neurite density from magnetic resonance diffusion measurements at ultrahigh field: comparison with light microscopy and electron microscopy. Neuroimage. 2010;49(1):205-216.

68. Jespersen SN, Kroenke CD, Ostergaard L, Ackerman JJ, Yablonskiy DA. Modeling dendrite density from magnetic resonance diffusion measurements. Neuroimage. 2007;34(4):1473-1486.

69. Zhang H, Schneider T, Wheeler-Kingshott CA, Alexander DC. NODDI: practical in vivo neurite orientation dispersion and density imaging of the human brain Neuroimage. 2012;64(4):1000-1016.

70. Santis S, Assaf Y, Evans CJ, Jones DK. Improved precision in CHARMED assessment of white matter through sampling scheme optimization and model parsimony testing. Magn Reson Med. 2014;71(2):661-671.

71. Panagiotaki E, Schneider T, Siow B, Hall MG, Lythgoe MF, Alexander DC. Compartment models of the diffusion MR signal in brain white matter: a taxonomy and comparison. Neuroimage. 2012;59(3):2241-2254.

72. Novikov D, Jespersen S, Kiselev V, Fieremans E. Quantifying brain microstructure with diffusion MRI: Theory and parameter estimation. NMR Biomed. this issue.

73. Sepehrband F, Alexander DC, Clark KA, Kurniawan ND, Yang Z, Reutens DC. Parametric Probability Distribution Functions for Axon Diameters of Corpus Callosum. Front Neuroanat. 2016;10:59.

74. Benjamini D, Komlosh ME, Holtzclaw LA, Nevo U, Basser PJ. White matter microstructure from nonparametric axon diameter distribution mapping. Neuroimage. 2016;135:333-344.

75. Drobnjak I, Zhang H, lanus A, Kaden E, Alexander DC. PGSE, OGSE, and sensitivity to axon diameter in diffusion MRI: Insight from a simulation study. Magn Reson Med. 2016;75(2):688-700.

76. Liewald D, Miller R, Logothetis N, Wagner HJ, Schuz A. Distribution of axon diameters in cortical white matter: an electron-microscopic study on three human brains and a macaque. Biol Cybern. 2014;108(5):541-557.

77. Thiebaut de Schotten M, Dell'Acqua F, Forkel SJ, et al. A lateralized brain network for visuospatial attention. Nat Neurosci. 2011;14(10):1245-1246.

78. Assaf Y, Blumenfeld, T, Levin, G, Yovel, Y, Basser, PJ. AxCaliber - A method to measure the axon diameter distribution and density in neuronal tissues. Proc Intl Soc Magn Reson Med. 2006;14:637.

79. Assaf Y, Blumenfeld-Katzir T, Yovel Y, Basser PJ. AxCaliber: a method for measuring axon diameter distribution from diffusion MRI. Magn Reson Med. 2008;59(6):1347-1354.

80. Barazany D, Basser PJ, Assaf Y. In-vivo Measurement of the Axon Diameter Distribution in the Rat's Corpus Callosum. Proc Intl Soc Magn Reson Med. 2008;16.

81. Horowitz A, Barazany D, Tavor I, Bernstein M, Yovel G, Assaf Y. In vivo correlation between axon diameter and conduction velocity in the human brain. Brain Struct Funct. 2015;220(3):1777-1788.

82. Zhang H, Hubbard PL, Parker GJ, Alexander DC. Axon diameter mapping in the presence of orientation dispersion with diffusion MRI. Neuroimage. 2011;56(3):13011315. 
83. Dyrby TB, Sogaard LV, Hall MG, Ptito M, Alexander DC. Contrast and stability of the axon diameter index from microstructure imaging with diffusion MRI. Magn Reson Med. 2012.

84. Dyrby TB, Sogaard LV, Hubbard PL, Hall MG, Ptito M, Alexander DC. Dependence of axon diameter index on maximum gradient strength. Proc Int/ Soc Magn Reson Med. 2010.

85. Huang SY, Nummenmaa A, Witzel T, et al. The impact of gradient strength on in vivo diffusion MRI estimates of axon diameter. Neuroimage. 2015;106:464-472.

86. Fieremans E, Burcaw LM, Lee HH, Lemberskiy G, Veraart J, Novikov DS. In vivo observation and biophysical interpretation of time-dependent diffusion in human white matter. Neuroimage. 2016;129:414-427.

87. Novikov DS, Jensen JH, Helpern JA, Fieremans E. Revealing mesoscopic structural universality with diffusion. Proc Natl Acad Sci U S A. 2014;111(14):5088-5093.

88. De Santis S, Jones DK, Roebroeck A. Including diffusion time dependence in the extra-axonal space improves in vivo estimates of axonal diameter and density in human white matter. Neuroimage. 2016;130:91-103.

89. Dell'Acqua F, Tournier JD. Reconstructing fiber orientations with diffusion MRI. NMR Biomed. this issue.

90. Thiebaut de Schotten M, Dell'Acqua F, Ratiu P, et al. From Phineas Gage and Monsieur Leborgne to H.M.: Revisiting Disconnection Syndromes. Cereb Cortex. 2015;25(12):4812-4827.

91. Mori S, Kaufmann WE, Pearlson G, et al. In vivo visualization of human neural pathways by magnetic resonance imaging. Ann Neurol. 2000;47(3):412-414.

92. Conturo TE, Lori NF, Cull TS, et al. Tracking neuronal fiber pathways in the living human brain. Proc Natl Acad Sci U S A. 1999;96(18):10422-10427.

93. Jones DK, Simmons A, Williams SC, Horsfield MA. Non-invasive assessment of axonal fiber connectivity in the human brain via diffusion tensor MRI. Magnetic Resonance in Medecine. 1999;42(1):37-41.

94. Mori S, Kaufmann W, Davatzikos C, et al. Imaging cortical association tracts in the human brain using diffusion-tensor-based axonal tracking. Magnetic resonance in medicine : official journal of the Society of Magnetic Resonance in Medicine / Society of Magnetic Resonance in Medicine. 2002;47(2):215-223.

95. Lawes INC, Barrick TR, Murugam V, et al. Atlas-based segmentation of white matter tracts of the human brain using diffusion tensor tractography and comparison with classical dissection. Neurolmage. 2008;39(1):62-79.

96. Oishi K, Zilles K, Amunts K, et al. Human brain white matter atlas: identification and assignment of common anatomical structures in superficial white matter. Neuroimage. 2008;43(3):447-457.

97. Mori $\mathrm{S}$, Oishi $\mathrm{K}$, Jiang $\mathrm{H}$, et al. Stereotaxic white matter atlas based on diffusion tensor imaging in an ICBM template. Neurolmage. 2008;40(2):570-582.

98. Catani M, Dell'acqua F, Vergani F, et al. Short frontal lobe connections of the human brain. Cortex. 2012;48(2):273-291.

99. Takemura H, Rokem A, Winawer J, Yeatman JD, Wandell BA, Pestilli F. A Major Human White Matter Pathway Between Dorsal and Ventral Visual Cortex. Cereb Cortex. 2016;26(5):2205-2214.

100. Yeatman JD, Weiner KS, Pestilli F, Rokem A, Mezer A, Wandell BA. The vertical occipital fasciculus: a century of controversy resolved by in vivo measurements. Proc Natl Acad Sci U S A. 2014;111(48):E5214-5223.

101. Mori S, van Zijl PC. Human white matter atlas. The American journal of psychiatry. 2007;164(7):1005.

102. Oishi K, Faria AV, van Zijl PCM, Mori S. MRI Atlas of Human White Matter. 2 ed: Elsevier; 2010.

103. Catani M, Thiebaut de Schotten M. Atlas of Human Brain Connections. Oxford: Oxford University Press; 2012. 
104. Klingler J. Erleichterung der makroskopischen Präparation des Gehirn durch den Gefrierprozess. Schweiz Arch Neurol Psychiat. 1935;36:247-256.

105. Klingler J, Gloor P. The connections of the amygdala and the anterior temporal cortex in the human brain. The Journal of Comparative Neurology. 1960;115(3):333369.

106. Yagmurlu K, Vlasak AL, Rhoton AL, Jr. Three-dimensional topographic fiber tract anatomy of the cerebrum. Neurosurgery. 2015;11 Suppl 2:274-305; discussion 305.

107. Catani M, Dell'acqua F, Thiebaut de Schotten M. A revised limbic system model for memory, emotion and behaviour. Neurosci Biobehav Rev. 2013;37(8):1724-1737.

108. Dell'acqua F, Scifo P, Rizzo G, et al. A modified damped Richardson-Lucy algorithm to reduce isotropic background effects in spherical deconvolution. Neuroimage. 2010;49(2):1446-1458.

109. Dell'Acqua F, Simmons A, Williams SC, Catani M. Can spherical deconvolution provide more information than fiber orientations? Hindrance modulated orientational anisotropy, a true-tract specific index to characterize white matter diffusion. Hum Brain Mapp. 2013;34(10):2464-2483.

110. Tournier JD, Calamante F, Connelly A. Robust determination of the fibre orientation distribution in diffusion MRI: non-negativity constrained super-resolved spherical deconvolution. Neuroimage. 2007;35(4):1459-1472.

111. Tournier JD, Calamante F, Gadian DG, Connelly A. Direct estimation of the fiber orientation density function from diffusion-weighted MRI data using spherical deconvolution. Neurolmage. 2004;23(3):1176-1185.

112. Tournier JD, Yeh $\mathrm{CH}$, Calamante $\mathrm{F}$, Cho KH, Connelly A, Lin CP. Resolving crossing fibres using constrained spherical deconvolution: validation using diffusion-weighted imaging phantom data. Neurolmage. 2008;42(2):617-625.

113. Mastropietro A, Scifo P, Rizzo G. Quantitative Comparison of Spherical Deconvolution Approaches to Resolve Complex Fiber Configurations in Diffusion MRI: ISRA-based vs L2L0 Sparse Methods. IEEE Trans Biomed Eng. 2017.

114. De Benedictis A, Petit L, Descoteaux M, et al. New insights in the homotopic and heterotopic connectivity of the frontal portion of the human corpus callosum revealed by microdissection and diffusion tractography. Hum Brain Mapp. 2016.

115. Jbabdi S, Sotiropoulos SN, Haber SN, Van Essen DC, Behrens TE. Measuring macroscopic brain connections in vivo. Nat Neurosci. 2015;18(11):1546-1555.

116. Rojkova K, Volle E, Urbanski M, Humbert F, Dell'Acqua F, Thiebaut de Schotten M. Atlasing the frontal lobe connections and their variability due to age and education: a spherical deconvolution tractography study. Brain Struct Funct. 2016;221(3):17511766.

117. Yagmurlu K, Middlebrooks EH, Tanriover N, Rhoton AL, Jr. Fiber tracts of the dorsal language stream in the human brain. J Neurosurg. 2016;124(5):1396-1405.

118. Nachev P, Kennard C, Husain M. Functional role of the supplementary and presupplementary motor areas. Nat Rev Neurosci. 2008;9(11):856-869.

119. Tomassini V, Jbabdi S, Klein JC, et al. Diffusion-weighted imaging tractographybased parcellation of the human lateral premotor cortex identifies dorsal and ventral subregions with anatomical and functional specializations. $J$ Neurosci. 2007;27(38):10259-10269.

120. Beckmann M, Johansen-Berg H, Rushworth MF. Connectivity-based parcellation of human cingulate cortex and its relation to functional specialization. $J$ Neurosci. 2009;29(4):1175-1190.

121. Ruschel M, Knosche TR, Friederici AD, Turner R, Geyer S, Anwander A. Connectivity architecture and subdivision of the human inferior parietal cortex revealed by diffusion MRI. Cereb Cortex. 2014;24(9):2436-2448.

122. Solano-Castiella E, Anwander A, Lohmann G, et al. Diffusion tensor imaging segments the human amygdala in vivo. Neurolmage. 2010;49(4):2958-2965.

123. Anwander A, Tittgemeyer $M$, von Cramon DY, Friederici AD, Knösche TR. Connectivity-Based Parcellation of Broca's Area. Cereb Cortex. 2007;17(4):816-825. 
124. Draganski B, Kherif F, Kloppel S, et al. Evidence for segregated and integrative connectivity patterns in the human Basal Ganglia. J Neurosci. 2008;28(28):71437152.

125. Thiebaut de Schotten M, Urbanski M, Valabregue R, Bayle DJ, Volle E. Subdivision of the occipital lobes: an anatomical and functional MRI connectivity study. Cortex. 2014;56:121-137.

126. Thiebaut de Schotten M, Urbanski M, Batrancourt B, et al. Rostro-caudal Architecture of the Frontal Lobes in Humans. Cereb Cortex. 2016.

127. Mars RB, Sallet J, Neubert FX, Rushworth MF. Connectivity profiles reveal the relationship between brain areas for social cognition in human and monkey temporoparietal cortex. Proc Natl Acad Sci U S A. 2013;110(26):10806-10811.

128. Mars RB, Jbabdi S, Sallet J, et al. Diffusion-weighted imaging tractography-based parcellation of the human parietal cortex and comparison with human and macaque resting-state functional connectivity. J Neurosci. 2011;31(11):4087-4100.

129. Sallet J, Mars RB, Noonan MP, et al. The organization of dorsal frontal cortex in humans and macaques. J Neurosci. 2013;33(30):12255-12274.

130. Mars RB, Foxley S, Verhagen L, et al. The extreme capsule fiber complex in humans and macaque monkeys: a comparative diffusion MRI tractography study. Brain Struct Funct. 2015.

131. Neubert FX, Mars RB, Sallet J, Rushworth MF. Connectivity reveals relationship of brain areas for reward-guided learning and decision making in human and monkey frontal cortex. Proc Natl Acad Sci U S A. 2015;112(20):E2695-2704.

132. Cerliani L, D'Arceuil H, Thiebaut de Schotten M. Connectivity-based parcellation of the macaque frontal cortex, and its relation with the cytoarchitectonic distribution described in current atlases. Brain Struct Funct. 2016.

133. Cerliani L, Thomas RM, Jbabdi S, et al. Probabilistic tractography recovers a rostrocaudal trajectory of connectivity variability in the human insular cortex. Human Brain Mapping. 2012;33(9):2005-2034.

134. Parker GD, Marshall D, Rosin PL, Drage N, Richmond S, Jones DK. A pitfall in the reconstruction of fibre ODFs using spherical deconvolution of diffusion MRI data. Neuroimage. 2013;65:433-448.

135. Jones DK, Knosche TR, Turner R. White matter integrity, fiber count, and other fallacies: the do's and don'ts of diffusion MRI. Neuroimage. 2013;73:239-254.

136. Jeurissen B, Leemans A, Tournier JD, Jones DK, Sijbers J. Investigating the prevalence of complex fiber configurations in white matter tissue with diffusion magnetic resonance imaging. Hum Brain Mapp. 2013;34(11):2747-2766.

137. Jones DK, Cercignani M. Twenty-five pitfalls in the analysis of diffusion MRI data. NMR Biomed. 2010;23(7):803-820.

138. Jones DK. Studying connections in the living human brain with diffusion MRI. Cortex. 2008;44(8):936-952.

139. Jbabdi S, Behrens TE. Long-range connectomics. Ann N Y Acad Sci. 2013;1305:8393.

140. Catani M. From hodology to function. Brain. 2007;130(Pt 3):602-605.

141. Kinoshita M, Yamada K, Hashimoto N, et al. Fiber-tracking does not accurately estimate size of fiber bundle in pathological condition: initial neurosurgical experience using neuronavigation and subcortical white matter stimulation. Neurolmage. 2005;25(2):424-429.

142. Fillard P, Descoteaux M, Goh A, et al. Quantitative evaluation of 10 tractography algorithms on a realistic diffusion MR phantom. Neuroimage. 2011;56(1):220-234.

143. Jbabdi S, Lehman JF, Haber SN, Behrens TE. Human and monkey ventral prefrontal fibers use the same organizational principles to reach their targets: tracing versus tractography. J Neurosci. 2013;33(7):3190-3201.

144. Thiebaut de Schotten M, Dell'acqua F, Valabregue R, Catani M. Monkey to human comparative anatomy of the frontal lobe association tracts. Cortex. 2012;48:82-96. 
145. Sotoripoulos S, Zalesky A. Building connectomes using diffusion MRI: Why, how and but. NMR Biomed. this issue.

146. Broca P. Sur le siege de la faculte du langage articule. Bull Soc Anthropol. 1865.

147. Damasio H, Damasio A. Lesion analysis in Neuropsychology. New York1989.

148. Bates E, Wilson S, Saygin A, et al. Voxel-based lesion-symptom mapping. Nature Neuroscience. 2003;6(5):448-450.

149. Karnath HO, Fruhmann Berger M, Küker W, Rorden C. The anatomy of spatial neglect based on voxelwise statistical analysis: a study of 140 patients. Cereb Cortex. 2004;14(10):1164-1172.

150. Rorden $\mathrm{C}$, Karnath $\mathrm{HO}$. Using human brain lesions to infer function: a relic from a past era in the fMRI age? Nat Rev Neurosci. 2004;5(10):813-819.

151. Husain M, Nachev P. Space and the parietal cortex. Trends in Cognitive Sciences. 2007;11(1):30-36.

152. Mah YH, Husain M, Rees G, Nachev $P$. Human brain lesion-deficit inference remapped. Brain. 2014;137(Pt 9):2522-2531.

153. Bartolomeo $P$, Thiebaut de Schotten $M$, Doricchi $F$. Left unilateral neglect as a disconnection syndrome. Cereb Cortex. 2007;17(11):2479-2490.

154. Bartolomeo P. The quest for the 'critical lesion site' in cognitive deficits: problems and perspectives. Cortex. 2011;47(8):1010-1012.

155. Thiebaut de Schotten $M$, Tomaiuolo $F$, Aiello $M$, et al. Damage to white matter pathways in subacute and chronic spatial neglect: a group study and 2 single-case studies with complete virtual "in vivo" tractography dissection. Cereb Cortex. 2014;24(3):691-706.

156. Rusconi E, Pinel P, Eger E, et al. A disconnection account of Gerstmann syndrome: functional neuroanatomy evidence. Ann Neurol. 2009;66(5):654-662.

157. Craig MC, Catani $M$, Deeley $Q$, et al. Altered connections on the road to psychopathy. Molecular Psychiatry. 2009;14(10):946-953, 907.

158. Zhao J, Thiebaut de Schotten M, Altarelli I, Dubois J, Ramus F. Altered hemispheric lateralization of white matter pathways in developmental dyslexia: Evidence from spherical deconvolution tractography. Cortex. 2016;76:51-62.

159. Thomas C, Avidan G, Humphreys K, Jung KJ, Gao F, Behrmann M. Reduced structural connectivity in ventral visual cortex in congenital prosopagnosia. Nat Neurosci. 2009;12(1):29-31.

160. Sanefuji M, Craig M, Parlatini V, et al. Double-dissociation between the mechanism leading to impulsivity and inattention in Attention Deficit Hyperactivity Disorder: A resting-state functional connectivity study. Cortex. 2016.

161. Catani M, Craig MC, Forkel SJ, et al. Altered Integrity of Perisylvian Language Pathways in Schizophrenia: Relationship to Auditory Hallucinations. Biol Psychiatry. 2011.

162. Hubl D, Koenig T, Strik W, et al. Pathways that make voices: white matter changes in auditory hallucinations. Arch Gen Psychiatry. 2004;61(7):658-668.

163. Shergill SS, Kanaan RA, Chitnis XA, et al. A diffusion tensor imaging study of fasciculi in schizophrenia. Am J Psychiatry. 2007;164(3):467-473.

164. ffytche DH. The hodology of hallucinations. Cortex. 2008;44(8):1067-1083.

165. Roberts RE, Anderson EJ, Husain M. White Matter Microstructure and Cognitive Function. Neuroscientist. 2013;19(1):8-15.

166. Johansen-Berg H, Della-Maggiore V, Behrens TEJ, Smith SM, Paus T. Integrity of white matter in the corpus callosum correlates with bimanual co-ordination skills. Neurolmage. 2007;36 Suppl 2:T16-21.

167. Braddick O, Atkinson J, Akshoomoff N, et al. Individual differences in children's global motion sensitivity correlate with TBSS-based measures of the superior longitudinal fasciculus. Vision research. 2016.

168. Tuch DS, Salat DH, Wisco JJ, Zaleta AK, Hevelone ND, Rosas HD. Choice reaction time performance correlates with diffusion anisotropy in white matter pathways 
supporting visuospatial attention. Proc Natl Acad Sci U S A. 2005;102(34):1221212217.

169. Baird AA, Colvin MK, Vanhorn JD, Inati S, Gazzaniga MS. Functional connectivity: integrating behavioral, diffusion tensor imaging, and functional magnetic resonance imaging data sets. J Cogn Neurosci. 2005;17(4):687-693.

170. Wong FC, Chandrasekaran B, Garibaldi K, Wong PC. White matter anisotropy in the ventral language pathway predicts sound-to-word learning success. J Neurosci. 2011;31(24):8780-8785.

171. Angstmann S, Madsen KS, Skimminge A, Jernigan TL, Baare WF, Siebner HR. Microstructural asymmetry of the corticospinal tracts predicts right-left differences in circle drawing skill in right-handed adolescents. Brain Struct Funct. 2016;221(9):4475-4489.

172. Thakkar KN, van den Heiligenberg FM, Kahn RS, Neggers SF. Speed of saccade execution and inhibition associated with fractional anisotropy in distinct fronto-frontal and fronto-striatal white matter pathways. Hum Brain Mapp. 2016;37(8):2811-2822.

173. Engel A, Hijmans BS, Cerliani L, et al. Inter-individual differences in audio-motor learning of piano melodies and white matter fiber tract architecture. Hum Brain Mapp. 2014;35(5):2483-2497.

174. Steele CJ, Scholz J, Douaud G, Johansen-Berg H, Penhune VB. Structural correlates of skilled performance on a motor sequence task. Front Hum Neurosci. 2012;6:289.

175. Roberts RE, Anderson EJ, Husain M. Expert cognitive control and individual differences associated with frontal and parietal white matter microstructure. $J$ Neurosci. 2010;30(50):17063-17067.

176. Gold BT, Powell DK, Xuan L, Jiang Y, Hardy PA. Speed of lexical decision correlates with diffusion anisotropy in left parietal and frontal white matter: evidence from diffusion tensor imaging. Neuropsychologia. 2007;45(11):2439-2446.

177. Floel A, de Vries $\mathrm{MH}$, Scholz J, Breitenstein C, Johansen-Berg $\mathrm{H}$. White matter integrity in the vicinity of Broca's area predicts grammar learning success. Neurolmage. 2009;47(4):1974-1981.

178. Klingberg T, Hedehus M, Temple E, et al. Microstructure of temporo-parietal white matter as a basis for reading ability: evidence from diffusion tensor magnetic resonance imaging. Neuron. 2000;25(2):493-500.

179. Deutsch GK, Dougherty RF, Bammer R, Siok WT, Gabrieli JD, Wandell B. Children's reading performance is correlated with white matter structure measured by diffusion tensor imaging. Cortex. 2005;41(3):354-363.

180. Thiebaut de Schotten M, Cohen L, Amemiya E, Braga LW, Dehaene S. Learning to read improves the structure of the arcuate fasciculus. Cereb Cortex. 2014;24(4):989995.

181. Keedwell PA, Doidge AN, Meyer M, Lawrence N, Lawrence AD, Jones DK. Subgenual Cingulum Microstructure Supports Control of Emotional Conflict. Cereb Cortex. 2016;26(6):2850-2862.

182. Bonnelle V, Ham TE, Leech $\mathrm{R}$, et al. Salience network integrity predicts default mode network function after traumatic brain injury. Proc Natl Acad Sci U $S$ A. 2012;109(12):4690-4695.

183. Wolbers T, Schoell ED, Buchel C. The predictive value of white matter organization in posterior parietal cortex for spatial visualization ability. Neuroimage. 2006;32(3):1450-1455.

184. Danielmeier C, Eichele T, Forstmann BU, Tittgemeyer M, Ullsperger M. Posterior medial frontal cortex activity predicts post-error adaptations in task-related visual and motor areas. $J$ Neurosci. 2011;31(5):1780-1789.

185. Klarborg B, Skak Madsen K, Vestergaard M, Skimminge A, Jernigan TL, Baare WF. Sustained attention is associated with right superior longitudinal fasciculus and superior parietal white matter microstructure in children. Hum Brain Mapp. 2013;34(12):3216-3232. 
186. Philp DJ, Korgaonkar MS, Grieve SM. Thalamic volume and thalamo-cortical white matter tracts correlate with motor and verbal memory performance. Neuroimage. 2014;91:77-83.

187. Takeuchi $\mathrm{H}$, Taki $\mathrm{Y}$, Sassa $\mathrm{Y}$, et al. White matter structures associated with creativity: evidence from diffusion tensor imaging. Neuroimage. 2010;51(1):11-18.

188. Bengtsson SL, Nagy Z, Skare S, Forsman L, Forssberg H, Ullen F. Extensive piano practicing has regionally specific effects on white matter development. Nat Neurosci. 2005;8(9):1148-1150.

189. Lewis GJ, Cox SR, Booth T, et al. Trait conscientiousness and the personality metatrait stability are associated with regional white matter microstructure. Social cognitive and affective neuroscience. 2016;11(8):1255-1261.

190. Fleming SM, Weil RS, Nagy Z, Dolan RJ, Rees G. Relating introspective accuracy to individual differences in brain structure. Science. 2010;329(5998):1541-1543.

191. Evans AC, Janke AL, Collins DL, Baillet S. Brain templates and atlases. Neuroimage. 2012;62(2):911-922.

192. Mesulam MM. Imaging connectivity in the human cerebral cortex: the next frontier? Ann Neurol. 2005;57(1):5-7.

193. Passingham RE, Stephan KE, Kotter R. The anatomical basis of functional localization in the cortex. NatRevNeurosci. 2002;3(8):606.

194. Zilles K, Amunts K. Anatomical basis for functional specialization. In: Uludağ K, Uğurbil K, Berliner L, eds. fMRI: From Nuclear Spins to Brain Functions. Vol 1. New York: Springer; 2015:27-66.

195. Johansen-Berg H, Behrens TE, Sillery E, et al. Functional-anatomical validation and individual variation of diffusion tractography-based segmentation of the human thalamus. Cereb Cortex. 2005;15(1):31-39.

196. Elias WJ, Zheng ZA, Domer P, Quigg M, Pouratian N. Validation of connectivitybased thalamic segmentation with direct electrophysiologic recordings from human sensory thalamus. Neuroimage. 2012;59(3):2025-2034.

197. Pouratian N, Zheng Z, Bari AA, Behnke E, Elias WJ, Desalles AA. Multi-institutional evaluation of deep brain stimulation targeting using probabilistic connectivity-based thalamic segmentation. J Neurosurg. 2011;115(5):995-1004.

198. Bartolomeo P, Seidel Malkinson T, de Vito S. Botallo's error, or the quandaries of the universality assumption. Cortex. 2017;86:176-185.

199. Thiebaut de Schotten M, Shallice T. Identical, similar or different? Is a single brain model sufficient? Cortex. 2017;86:172-175.

200. Cerliani L, Thomas RM, Aquino D, Contarino V, Bizzi A. Disentangling subgroups of participants recruiting shared as well as different brain regions for the execution of the verb generation task: A data-driven fMRI study. Cortex. 2017;86:247-259.

201. Tzourio-Mazoyer N, Perrone-Bertolotti M, Jobard G, Mazoyer B, Baciu M. Multifactorial modulation of hemispheric specialization and plasticity for language in healthy and pathological conditions: A review. Cortex. 2017;86:314-339.

202. Parlatini V, Radua J, Dell'Acqua F, et al. Functional Segregation and Integration within Fronto-Parietal Networks. Neuroimage. 2016.

203. Catani M, Allin MP, Husain M, et al. Symmetries in human brain language pathways correlate with verbal recall. Proc Natl Acad Sci U S A. 2007;104(43):17163-17168.

204. Mazoyer B, Zago L, Jobard G, et al. Gaussian mixture modeling of hemispheric lateralization for language in a large sample of healthy individuals balanced for handedness. PLoS One. 2014;9(6):e101165.

205. Forkel SJ, Thiebaut de Schotten M, Dell'Acqua F, et al. Anatomical predictors of aphasia recovery: a tractography study of bilateral perisylvian language networks. Brain. 2014;137(Pt 7):2027-2039.

206. Lunven M, Thiebaut De Schotten M, Bourlon C, et al. White matter lesional predictors of chronic visual neglect: a longitudinal study. Brain. 2015;138(Pt 3):746-760.

207. Cercignani M, Wheeler-Kingshott CA. From micro- to macro-structures in multiple sclerosis: What can we learn from diffusion imaging? NMR Biomed. this issue. 
208. Hess CW. Diffusion MRI in clinical practice. NMR Biomed. this issue.

209. Sotiropoulos SN, Jbabdi S, Xu J, et al. Advances in diffusion MRI acquisition and processing in the Human Connectome Project. Neuroimage. 2013;80:125-143.

210. Le Bihan D, Urayama S, Aso T, Hanakawa T, Fukuyama H. Direct and fast detection of neuronal activation in the human brain with diffusion MRI. Proc Natl Acad Sci USA. 2006;103(21):8263-8268.

211. Le Bihan D. Looking into the functional architecture of the brain with diffusion MRI. Nat Rev Neurosci. 2003;4(6):469-480.

212. Lebel C, Treit S, Beaulieu C. Diffusion MRI of typical white matter development from childhood to adulthood. NMR Biomed. this issue.

213. Bruel-Jungerman E, Davis S, Laroche S. Brain plasticity mechanisms and memory: a party of four. Neuroscientist. 2007;13(5):492-505.

214. Bruel-Jungerman E, Rampon C, Laroche S. Adult hippocampal neurogenesis, synaptic plasticity and memory: facts and hypotheses. Rev Neurosci. 2007;18(2):93114.

215. Holtmaat A, Svoboda K. Experience-dependent structural synaptic plasticity in the mammalian brain. Nat Rev Neurosci. 2009;10(9):647-658.

216. Butz M, Worgotter F, van Ooyen A. Activity-dependent structural plasticity. Brain Res Rev. 2009;60(2):287-305.

217. Theodosis DT, Poulain DA, Oliet SH. Activity-dependent structural and functional plasticity of astrocyte-neuron interactions. Physiological reviews. 2008;88(3):9831008.

218. Muller D, Nikonenko I, Jourdain P, Alberi S. LTP, memory and structural plasticity. Current molecular medicine. 2002;2(7):605-611.

219. Hihara S, Notoya T, Tanaka M, et al. Extension of corticocortical afferents into the anterior bank of the intraparietal sulcus by tool-use training in adult monkeys. Neuropsychologia. 2006;44(13):2636-2646.

220. Dancause N, Barbay S, Frost SB, et al. Extensive cortical rewiring after brain injury. The Journal of neuroscience. 2005;25(44):10167-10179.

221. Johansen-Berg $\mathrm{H}$. Structural plasticity: rewiring the brain. Curr Biol. 2007;17(4):R141-144.

222. Scholz J, Klein MC, Behrens TE, Johansen-Berg H. Training induces changes in white-matter architecture. Nat Neurosci. 2009;12(11):1370-1371.

223. Blumenfeld-Katzir T, Pasternak O, Dagan M, Assaf Y. Diffusion MRI of structural brain plasticity induced by a learning and memory task. PLoS One. 2011;6(6):e20678.

224. Wake H, Lee PR, Fields RD. Control of local protein synthesis and initial events in myelination by action potentials. Science. 2011;333(6049):1647-1651.

225. Thomas $\mathrm{C}$, Baker $\mathrm{Cl}$. Teaching an adult brain new tricks: a critical review of evidence for training-dependent structural plasticity in humans. Neuroimage. 2013;73:225-236. 